\title{
Design of a Hydraulic Lift Platform
}

\author{
Yan Wei, Hui Li, Hu Gao \\ Zaozhuang Vocational College of Science \& Technology, Tengzhou, 277599, China \\ E-mail: lihui125@126.com
}

Keywords: hydraulics, lift platform, design

\begin{abstract}
This paper designs a hydraulic lift platform which can smoothly transport goods up and down. The transport platform is composed of a lifting cylinder, pulley blocks and steel wire ropes, which can cover a wide range of lifting heights by making use of a single lifting cylinder with a relatively short stroke. When it rises, it climbs up by a hydraulic-driven lifting cylinder, and when it descends, it glides down by self-gravity and unloads force by hydraulic pump, which saves energy greatly. The hydraulic lift platform is easy to control and convenient to use, having a broad application value.
\end{abstract}

\section{Introduction}

In our daily life, we often use various kinds of lift platforms to reduce manual labor and cost. This paper applies hydraulic technology to designs a hydraulic lift platform which can smoothly transport goods up and down. It is small in installation space, long in working stroke and sample in structure. The combination of multiple pulley blocks and steel wire ropes solves the problem of instability in the process of rising resulting from the large size of the work surface and enhances the stability as well as the performance of the platform. A hydraulic cylinder is used to lock the work surface, which improves the platform's operational safety. And due to the fact that there is only one hydraulic-driven lifting cylinder, the platform is greatly simplified, avoiding the synchronization problem caused by adopting multiple lifting cylinders and having a low manufacturing cost. The hydraulic lift platform is sample in structure and stable in operation, having a broad application value.

\section{Schematic Diagram}

The schematic diagram of the hydraulic lift platform is shown in Figure1.

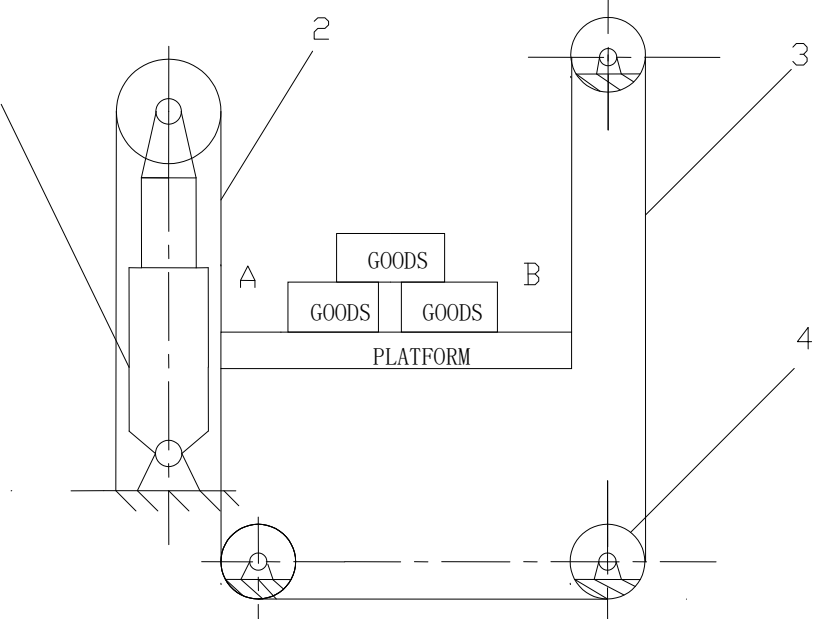

Figure1Schematic Diagram of Hydraulic Lift Platform

1. Hydraulic cylinder; 2. A steel wire rope; 3 . Three steel wire rope; 4 . Three pulley blocks 
The work surface is a welded steel-frame structure and the column applies the guide rail structure. A pulley is installed on the rod of the hydraulic cylinder and steel wire ropes are adopted to connect four lifting points. The conditions of the system are as follow: Start $\rightarrow \mathrm{Up} \rightarrow$ Lock $\rightarrow$ Down $\rightarrow$ Lock, followed by recycling.

The technical parameters of the system are as follow:

work surface size: $3 \mathrm{~m} \times 2 \mathrm{~m}$;

lifting weight: $3 t$;

lifting height: $3 \mathrm{~m}$;

rising time: less than 1 min;

descending time: less than 1 min.

\section{Operating Principles}

The operating principles of the hydraulic lift platform are as follows.

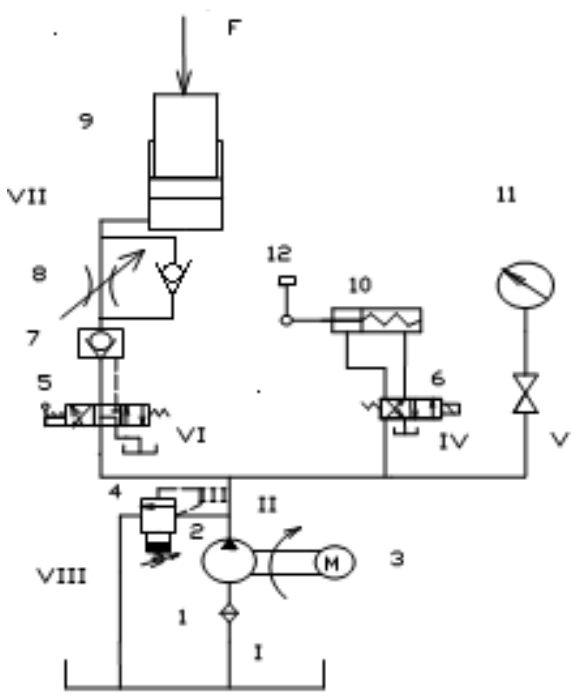

When the platform rises:

Figure2 Diagram of Hydraulic System

First, start the hydraulic pump (2). With the 1 YA electromagnet being energized, the directional valve (6) is switched to the right position. Meanwhile, switchthe manually operated directional valve (5) to the right position. At the moment, the pressure oil in the hydraulic pump (2) flows into the rod chamber of the lock cylinder (10) and the working chamber of the plunger cylinder (9), which leads the piston rod of the lock cylinder (10) retract and the plunger cylinder (9) rise. When the plunger cylinder (9) rises to 1.5 meters, the work surface touches the sensor of the directional valve (6), which makes the 1 YA electromagnet being de-energized and the directional valve (6) being switched back to the left position. At the moment, the pressure oil flows through the directional valve (6) to the rear chamber of the lock cylinder (10), which leads the piston rod of the lock cylinder (10) extend out to lock the work surface. After the stroke switch (12) sends out a safety signal, switch the manually operated directional valve (5) back to the neutral position. With force being unloaded by the Y-type neutral position of the manually operated directional valve (5), the hydraulic pump (2) is stopped.

When the platform descends:

First, start the hydraulic pump (2) and switch the manually operated directional valve (5) to the left position. With the 1 YA electromagnet being energized, the directional valve (6) is switched to the right position. At the moment, the pressure oil flows into the rod chamber of the lock cylinder (10). When the piston rod of the lock cylinder (10) retracts, the work surface is unlocked. The pressure oil then opens the pilot-controlled check valve (7) and flows through the restrictive valve (8), the pilot-controlled check valve (7) and the manually operated directional valve (5) to the reservoir. The platform glides down by the gravity of the work surface and the reservoir, with the 
falling time being controlled by the opening degree of the restrictive valve (8).

\section{Calculation of External Loads}

Table1 Loads of Hydraulic Cylinder in All Conditions

\begin{tabular}{|l|l|c|c|}
\hline Condition & Formula & $\begin{array}{l}\text { Loads of hydraulic cylinder } \\
(\mathrm{N})\end{array}$ & $\begin{array}{l}\text { Thrust of hydraulic cylinder } \\
(\mathrm{N})\end{array}$ \\
\hline Start & $F_{\text {total }}=f F_{g}+2 F$ & 60270 & 66967 \\
\hline Up & $F_{\text {total }}=f F_{g}+2\left(F+F_{m \text {-up }}\right)$ & 62070 & 68697 \\
\hline Lock & $F_{\text {total }}=f F_{g}+2 F$ & 60270 & 66967 \\
\hline Down & $F_{\text {total }}=f F_{g}+2 F$ & 16758 & 18620 \\
\hline Lock & $F_{\text {total }}=f F_{g}+2\left(F+F_{m \text {-down }}\right)$ & 16278 & 18087 \\
\hline
\end{tabular}

\section{Load and Speed of Hydraulic Cylinder}

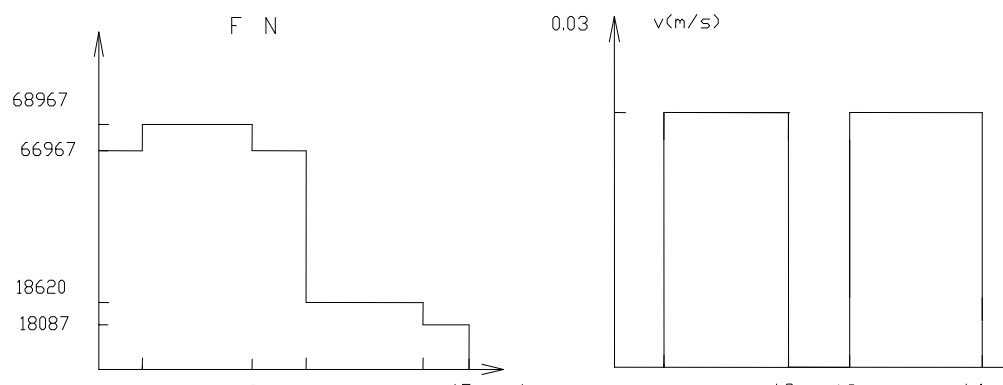

Figure3 Load Diagram of Hydraulic Cylinder Figure4 Speed Diagram of Hydraulic Cylinder

\section{Parameters of Hydraulic Cylinder}

Following the design goal of simple structure and easy operation, a single-acting plunger-type hydraulic cylinder with a stroke of 1.5 meters is selected as the actuator of the platform in this paper.

The maximum thrust of the hydraulic cylinder is $F_{\max }=68697 N$, and the working pressure of the primary system is $P=10 \mathrm{MPa}$. According to the formula

$$
D=\sqrt{\frac{4 F_{1}}{\pi P}} \times 10^{-3} \mathrm{~m}
$$

the inner diameter of the hydraulic cylinder should be $D=93.7 \times 10^{-3} \mathrm{~m}$.

According to the above-mentioned inner diameter, this paper selects the following single-acting plunger-type hydraulic cylinder.

\begin{tabular}{|c|c|c|c|c|}
\hline Model & $\begin{array}{c}\text { Plunger } \\
\text { diameter/mm }\end{array}$ & Rated pressure/MPa & Thrust/KN & $\begin{array}{c}\text { Maximum } \\
\text { stroke/mm }\end{array}$ \\
\hline ZG-E110 & 110 & 16 & 166 & 1500 \\
\hline
\end{tabular}

\section{Hydraulic Components}

\subsection{Hydraulic Pump}

In the design, the movement of the actuator requires the maximum pressure. After taking into account local losses and losses along the inlet oil line, the maximum working pressure of the hydraulic pump is:

$$
P_{p}=P_{1}+\sum \Delta P=7.26+0.4=7.66 \mathrm{MPa}
$$

The output flow of the hydraulic pump is: 


$$
Q_{p}=1.15 \times 0.285 \times 10^{-3} \approx 0.328 \times 10^{-3} \mathrm{~m}^{3} / \mathrm{s}
$$

In order to make the hydraulic pump have a certain level of pressure reserves, the rated pressure of the selected one should be $25 \%-60 \%$ larger than the maximum working pressure. This paper applies $25 \%$, and the rated pressure of the selected hydraulic pump should be:

$$
P_{n} \geq 1.25 P_{n}=1.25 \times 7.66=9.575 \mathrm{MPa}
$$

According to the above-mentioned value, $P_{n}$ and $Q_{n}$, and features of the hydraulic system in this paper, the selected hydraulic pump should be a high-pressure low-volume constant-flow one. This paper chooses CEN-E310 Gear Pump with a rated pressure of $16 \mathrm{MPa}$, a displacement of $10 \mathrm{ml} / \mathrm{r}$ and a speed of $2000 \mathrm{r} / \mathrm{min}$, which can meet the pressure and flow requirements of the system.

In the working process of the hydraulic system, the pressure and flow are relatively constant. Thus, the driving power of the pump should be:

$$
P=\frac{P_{p} Q_{0}}{\eta_{p}}=\frac{P_{p} q_{p t} n_{n}}{\eta_{p}}=\frac{7.66 \times 10^{6} \times 10 \times 10^{-6} \times 2000}{60 \times 0.83}=3076 \mathrm{~W}
$$

In this paper, Y112M-4 Motor is chosen to drive the hydraulic pump. Its rated power is $4 \mathrm{Kw}$ and its rated speed is $1440 \mathrm{r} / \mathrm{min}$.

\subsection{Pressure Relief Valve}

In the hydraulic system of the lift platform, the maximum working pressure of the pressure relief valve is equal to the maximum pressure of the hydraulic pump, $P_{p}$, and the flow of the pressure relief valve is also equal to that of the pump, $Q_{p}$. According to the value, $P_{p}$ and $Q_{p}$, this paper selects DBD-H6P Pressure Relief Valve with a pressure of $31.5 \mathrm{Mpa}$, a rated flow of $50 \mathrm{~L} / \mathrm{min}$ and a voltage range of $5 \mathrm{MPa}$ to $10 \mathrm{MPa}$.

7.3 Manually Operated Directional Valve

Following the design goal of simple structure and easy operation, a manually operated directional valve is applied in the design. The choice of the manually operated directional valve mainly depends on the working pressure of the hydraulic system and the maximum flow that actually passes through the valve. It is notable that the selection of the neutral function of the valve is the most important thing. This paper chooses 4WMM6J50, a three-position four-way manually operated directional valve, which can meet the design requirements of the hydraulic system and is with a Y-type neutral function.

\subsection{Lines}

Line I:

This line is the pump's inlet oil line. After calculation, a cold-drawn seamless steel tube with a nominal inner diameter of $20 \mathrm{~mm}$, a thickness of $1.6 \mathrm{~mm}$ and an outer diameter of $28 \mathrm{~mm}$ is selected as Line I.

Line II, III, IV, V:

High pressure oil flows through these lines. After calculation, cold-drawn seamless steel tubes with a nominal inner diameter of $10 \mathrm{~mm}$, a thickness of $2 \mathrm{~mm}$ and an outer diameter of $18 \mathrm{~mm}$ are applied.

Line VII:

This line is always under high pressure, when the platform rises. After calculation, the 10II-1500JB1885-77 Hose with an inner diameter of $10 \mathrm{~mm}$ and a length of $1500 \mathrm{~mm}$ is chosen as Line VII.

Line VI, VIII:

Line VI and VII both work as the return line, when the hydraulic pump supply oil to the hydraulic cylinder. After calculation, cold-drawn seamless steel tubes with a nominal inner diameter of $15 \mathrm{~mm}$, a thickness of $1.6 \mathrm{~mm}$ and an outer diameter of $22 \mathrm{~mm}$ are applied, since the pressure on them is small.

7.5 Details of Selected Hydraulic Components

The specification and model of the selected hydraulic components are shown in Table2. 
Table2 Detailed List of Selected Hydraulic Components

\begin{tabular}{|c|c|c|c|}
\hline No. & Component Name & Model & Count \\
\hline 1 & Gear pump & $\mathrm{CBN}-\mathrm{E} 310$ & 1 \\
\hline 2 & Pressure relief valve & DBD-H6P & 1 \\
\hline 3 & $\begin{array}{l}\text { Manually operated } \\
\text { directional valve }\end{array}$ & 4WMM6J50 & 1 \\
\hline 4 & $\begin{array}{c}\text { Two-position four-way } \\
\text { electromagnetic } \\
\text { directional valve }\end{array}$ & 4WE10-20/W220-50 & 1 \\
\hline 5 & $\begin{array}{l}\text { Pilot-controlled check } \\
\text { valve }\end{array}$ & SV10P-30 & 1 \\
\hline 6 & $\begin{array}{l}\text { Plunger-type hydraulic } \\
\text { cylinder }\end{array}$ & ZG-E110 & 1 \\
\hline 7 & Pressure gauge & $Y-100$ & 1 \\
\hline 8 & Pressure gauge switch & $\mathrm{KF}-\mathrm{L} 8 / 14 \mathrm{E}$ & 1 \\
\hline 9 & Suction filter & WU- $63 \times 180$ & 1 \\
\hline 10 & $\begin{array}{c}\text { Liquid level and } \\
\text { temperature measuring } \\
\text { instrument }\end{array}$ & YWZ-80T & 1 \\
\hline
\end{tabular}

\subsection{Reservoir Capacity}

The capacity of the reservoir is first calculated with an empirical formula. After all other parameters being determined, the capacity is verified to meet the heat dissipation requirement of the hydraulic system. Finally, the capacity of the reservoir is:

$$
V=0.8 a b h=0.8 \times 0.85 \times 0.46 \times 0.46=0.1439\left(m^{3}\right)=143.9 L
$$

\section{Conclusion}

This paper aims to apply hydraulic technology to control the rise and fall of the lift platform. This paper fulfils the following tasks:

(1) The design of the hydraulic lift platform and the hydraulic system has been completed. Important diagrams, including Diagram of Hydraulic System and Schematic Diagram of Hydraulic Lift Platform, have been drawn.

(2) After several calculations and modifications, the pressure station of the hydraulic lift platform has a strong controllability, which can effectively control hydraulic molding devices. The hydraulic lift platform is easy to control and stable in operation, meeting the design goal.

\section{References}

[1] Hao, Xu. 2000. Mechanical Design Manual Volume 5 - Hydraulic System Design (2 ${ }^{\text {nd }}$ Version) [M]. China Machine Press.

[2] Shoucheng, Wang. \& D. Junyong. 2007. Hydraulic Components and Selection [M]. Chemical Industry Press.

[3]Guihua,Fang. 2002.Hydraulic Drive[M]. Seismological Press.

[4] Goodwin, A.B. 1976. Fluid Power System [M].

[5] Smith, I. E., S. D. Probert, R. E. Stokes\& R. J. Hansford. 1977. The Briquetting of Wheat Straw [J]. Journal of Agricultural Engineering Research. (22): 105-111. 